\title{
A qualitative exploration of the recovery experiences of consumers who had undertaken shared management, person-centred and self-directed services
}

\author{
Angus Buchanan ${ }^{1 *}$, Sunila Peterson ${ }^{1}$ and Torbjorn Falkmer ${ }^{1,2,3}$
}

\begin{abstract}
Background: The mental health sector across states in Australia is moving to offering individualised funds and shared management, person-centred and self-directed (SPS) services. However, little is known about the recovery experiences of consumers with mental illness who had used a SPS service that was recently introduced in Western Australia. This study explored the recovery experiences of these consumers.

Methods: Data relating to sixteen consumers' lived experiences were analysed using an abbreviated grounded theory approach. These data had been developed in the past by consumers, the Guides (staff) and an independent evaluator.

Results: Four over-arching categories, and related sub-categories, emerged. These suggested that consumers' recovery experiences included them gaining: 1) a greater sense of empowerment; 2) expanded connections with the community, others and 'the self'; 3) an enriched sense of 'the self'; and 4) an enhanced quality of life.

Conclusions: Access to SPS services, including having access to individualised funds, high quality shared management and person-centred relationships with the Guides, and a chance to self-direct services enabled consumers to have control over all aspects of their recovery journey, facilitated change and growth, and improved their capacity to self-direct services. Most consumers encountered a number of positive recovery experiences at varied levels that enhanced their lived experiences.
\end{abstract}

Keywords: Grounded theory, Mental health reformation, Self-direction

\section{Background}

Service provision impacts on the health outcomes of consumers of mental health services [1]. In the mental health sector, dissatisfaction with the predominant biomedical model of service has facilitated the evolution of more consumer focused services [2-4]. The biomedical model is criticised for viewing mental illness as a biological disease based problem, effective treatment as the curing of this biological problem, and consumers as passive patients with the problem and receivers of treatment $[2,5,6]$. The biomedical model has provided invaluable

\footnotetext{
* Correspondence: A.Buchanan@curtin.edu.au

${ }^{1}$ School of Occupational Therapy \& Social Work, Curtin University, Perth, WA, Australia

Full list of author information is available at the end of the article
}

empirically sound methodology for understanding mental illness and also promoted the acceptance of some mental illness and treatments [2,5,7]. However, it is criticised for not meeting consumers' recovery needs adequately [2,5].

Consumers' recovery needs commonly relate to areas of work, home, education, spirituality, pets, interpersonal relationships, and health and wellbeing [2]. Consumers' reports suggest they want to be viewed as capable of managing their needs, and desire active participation, responsibility, flexibility, and equality in working with service providers (agencies that consumers seek mental health services from) to identify and manage their recovery journey $[2,8-10]$. Services underpinned by a biomedical model may view recovery clinically as being cured of 
the biological dysfunction underlying mental illness with an outcome of observed symptom reduction, which may not adequately address and/or meet consumers' recovery needs [11-15]. More expansively, recovery may be understood as a personal journey made by consumers over time where they move towards building a fulfilling and meaningful life, living with and beyond their mental illness, and experiencing a positive sense of identity founded on hope and self-determination $[10,11,15]$. Personal recovery is best evaluated by consumers, does not require symptom reduction, and/or need to be associated with mental health service treatment outcomes [15]. Furthermore, it accommodates varied types of recovery goals, effective treatments, and outcomes that differ across consumers [15].

Consumers' dissatisfaction from not having their needs met by services embedded in a biomedical model, alongside improved service practice in the disability sector, has facilitated the evolution of more consumer focused services [10,15-17]. Such consumer focused services are based on a self-directed service model $[8,9]$ that seeks to facilitate consumers' active participation in their recovery, empower them to define and identify their unique needs, and support them to procure recovery resources (goods and services) that will adequately meet these needs $[8,9]$. Such services may provide consumers' access to shared-management and person-centred relationships to enable them to self-direct (SPS) services [18]. Consumers may also receive allocated money from the service provider (e.g., individualised funds, personal budgets or direct payments) to access resources that have been endorsed for procurement by the service provider, to meet their recovery needs. These individualised funds may be managed by consumers or a person (e.g., from personal network or the service provider) chosen by them $[8,9,18,19]$.

SPS services provide consumers with access to shared management and person-centred relationships with staff, such as a broker, advisor, guide, mentor, or support worker. Shared management requires both consumers and staff to be responsible for managing individualised funds and recovery resources, and staff to support consumers' freedom, responsibility, and accountability in progressing their recovery journey $[2,8,16,20,21]$. High quality relationships are developed when staff are empathic and attuned to consumers' needs, reactions and experiences, which are understood as being distinct from their own needs, reactions and experiences [17,22-24]. Staff's use of open and sensitive communication also enhances the quality of relationships, establishing and maintaining clear relationship boundaries that support consumers' autonomy and independence, while enabling them to collaboratively work through emerging challenges [17,22-24].

Further, in SPS services the provision of shared management and person-centred relationships place consumers at the centre of their service and use their expertise in person-centred planning (PCP) to design recovery plans tailored to meet their unique needs $[2,8,9,25]$. In these relationships, staff listen, hear, understand, and respect consumers, and provide them freedom and responsibility to self-direct (e.g., have full control, make decisions, and engage actions as they desire) their recovery journey using individualised funds $[2,8,9,14,15,18,19,21]$. Thus, shared management and person-centred relationships support consumers to self-direct their SPS services. Such services enhance consumers' opportunity to have their recovery needs known and met in meaningful and satisfactory ways, and optimise their chance for experiencing personal recovery $[10,11,15]$.

Research from other countries show that SPS services has provided consumers' experiences of improved employment and educational opportunities, enhanced meaning and hope in life, and enriched self-belief, self-esteem and/ or wellbeing $[8,9,18,21]$. Some SPS service consumers are also found to expand their connections with 'the self', other individuals, and the general community for social, professional and/or recreational purposes from which their sense of self-control and confidence may be enhanced [8,9,26]. A few SPS service consumers have reported less illness symptoms, lower relapse rates and use of medication and/or income support, and better mental health functioning and use of preventative, rather than acute, services $[8,18]$. Thus, research results suggest that SPS service consumers experience an improved quality of life from having their whole of life needs met $[8,9,18,21,26,27]$. Further, SPS service consumers have reported higher levels of service satisfaction, which promotes their opportunity for the proactive use of services that may benefit them, those related to them, and the community $[8,9,21]$.

These advancements in mental health services that have evolved for decades internationally across the disability and, more recently, the mental health sector are currently being officially incorporated into services by service providers within states across Australia [14,25,28]. In the state of Western Australia (WA), a service provider invited sixteen consumers of mental health services, over a selection period of two to three weeks, to participate in a pilot SPS service. All consumers accepted and started the SPS service by attending an information session. They then completed five fortnightly small group person-centred planning (PCP) sessions, over three months, working with various staff of the service provider (e.g., PCP facilitators or support workers), friends, and/or family to identify their 'future dreams'. Once the PCP was completed, consumers began working with one of two Guides (also staff employed by the service provider) in shared management and person-centred relationships. The Guides were available to consumers from selection, throughout the PCP process, and the development and 
implementation of their action plans (twelve months). The Guides provided the most concentrated levels of support during weekly visits with each consumer (two to six weeks) to develop their future dreams into recovery goals on their action plans. These action plans, once endorsed for funding by the service provider, became the 'map' from which the consumers navigated their recovery journey. Consumers were given flexibility to update their action plans to accommodate unpredictable and changing circumstances throughout the service period. The Guides then worked with consumers to implement their action plans, manage their individualised funds, and/or prepare for PCP reunion gatherings. During this time, the Guides moved to fortnightly visits, and then gradually to monthly visits, based on consumers' needs. Throughout, these consumers also had access to support from support workers, family and friends, and individuals or groups in the community.

The service provider's initiative was innovative in that they were one of the first organisations to offer SPS services to consumers with mental illness in WA, based on the belief that such services provide best practice in meaningfully and effectively meeting consumers' recovery needs. Although research from other countries suggest that SPS services provide for effective recovery experiences, little is known about the recovery experiences of consumers undertaking newly offered services in states across Australia. The WA service provider, who had recently delivered a SPS service, engaged the authors to evaluate and develop a pilot model of service practice for use across the WA mental health sector. This study explored one of three general sections of the pilot model of service practice that was developed, which related to the research aim, using the perspectives of consumers, alongside others who had undertaken the SPS service [12,15,29-31].

\section{Aim}

This study explored the recovery experiences of consumers with mental illness who had undertaken a pilot SPS service.

\section{Methods \\ Design}

This study analysed data that had been compiled in the past. At that time, data on both retrospective and contemporary experiences were collected. The data were related to sixteen consumers with mental illness who had participated in a pilot SPS service. This method is also reported elsewhere [17].

\section{Materials}

Consumers of the SPS service, who self-selected into the study, consented for researchers to have access to de- identified data of their lived experiences while undertaking SPS services. Lived experiences reflected consumers' accounts of what life was like, while living with and beyond their mental illness [15]. The data were held by the service provider and an independent evaluator. Overall, the data on 473 documents related to consumers' lived experiences prior to and while they were undertaking services (Tables 1 and 2). These data had been developed by three sources including the consumers, two Guides and another evaluator independent of the researchers/ authors. The data developed by sixteen consumers were held by the service provider. The Guides provided the researchers with consumers' action plans, two questionnaires ('Most Important Changes (MIC) to My Life' completed one to four times and 'Recovery') that had been completed for the independent evaluator prior to the commencement of this study, and PCP reunion speeches. The Guides also provided the researchers with documents they had developed on their personal learning and reflections of consumers' progress and service aspects (completed four to seven times per group), meeting minutes, and own PCP reunion speeches. The independent evaluator who had evaluated the PCP process three times for the service provider gave the researchers interview (of consumers and staff) and evaluation (three key note summaries and full) report data. The data developed by the three sources varied in the type (e.g., background, experiences around living with mental illness, hopes, and experience of the SPS service) and style of information that was captured (e.g., bullet point, short answer, Likert scale, or narrative) as described in Table 1.

\section{Recruitment of consumers and their demographic characteristics}

Of the sixteen consumers who used the SPS service and self-selected into the study, twelve had used other services from the service provider prior to beginning the SPS service, and four were new referrals. Consumers were invited to undertake the SPS service if the service provider's staff thought they were ready to use the service. The Guides, sometimes with other staff (e.g., a support worker or manager), visited potential consumers at their homes, discussed aspects of the SPS service, and responded to consumers' questions. Consumers who wanted to use the SPS service contacted the Guides to progress their recruitment. All sixteen consumers invited to use the SPS service had undertaken this service across three groups that commenced about six months apart. These sixteen consumers consented to participate in the study. At the time of the study, seven consumers had completed the SPS service but were keeping in regular contact with the Guides, and three consumers were still implementing their action plans sixteen months since commencing the SPS service. The last group of six 
Table 1 Description of data documents provided by three data sources

\begin{tabular}{|c|c|c|}
\hline Data sources & $\begin{array}{l}\text { Types of de-identified data } \\
\text { documents }\end{array}$ & Description of information \\
\hline Independent evaluator & \multirow{2}{*}{$\begin{array}{l}\text { Consumer interview (past** } \\
\text { and current*** experiences) } \\
\text { reports }\end{array}$} & \multirow{2}{*}{$\begin{array}{l}\text { Consumers' interview data (e.g., questions, responses, } \\
\text { and summarising) of reflections since undertaking the } \\
\text { SPS service were collated into three full and summary } \\
\text { reports }\end{array}$} \\
\hline $\begin{array}{l}\text { Evaluator assessing the PCP* component of SPS } \\
\text { services (data compiled in the past on consumers' } \\
\text { past and current experiences) }\end{array}$ & & \\
\hline
\end{tabular}

PCP evaluation reports Evaluation reports provided to the organisation reflecting the evaluators' interpretation of consumers' and staffs' data in relation to their undertaking of the PCP component of the SPS service

Staff interviews (past and current experiences)

\section{The guides}

Staff who supported consumers through shared management and person-centred relationships across all phases of the SPS service. Data (documented in the past) related to the consumers' progress and program implementation experiences in the past (retrospective) and at that time (current)

\section{Consumers}

Consumers who undertook SPS services in three groups of 5 - 6 members about six months apart, over a total period of 16 months. Data (documented in the past) related to consumers' experiences in the past (retrospective) and at that time (current) experiences) reunion events that captured the Guides' experiences
Personal learning (past experiences)

Organisational reports (past and current experiences)

Reflections on consumers (past and current experiences)

Reflections on the services (past and current experiences)

Speeches (past and current experiences)

Action plans (current

Most important changes (MIC) in my life questionnaire (current experiences)

Recovery questionnaire (past and current experiences)

Speeches (past and current experiences)
Staffs' interview data collated into reports based on the Guides' and other staffs' reflections

The Guides' reflections on their learning of service administration and process (e.g., how best to support consumers to enable their achievement of recovery goals and self-direction)

Reports provided to key organisational stakeholders at irregular meetings on the progress of the consumers

Guides' reflections on what was done; what worked; what could improve and the next steps in relation to consumers' achievement of recovery goals and self-direction completed up to 4-7 times per group

Reflections on what was done; what worked; what could improve and the next steps in relation to their administration of services to support consumers through the SPS service

Speeches prepared and presented by the Guides for working with the participants and the SPS service

Fine-tuned from consumers' dreams identified during PCP process. These defined their recovery goals including: change they wanted to achieve; the first steps they need to take; who they want to work with; when they want to take the first steps; and the costs that will be involved. Recovery goals on any action plan ranged from 4 - 10

Open and closed ended questions forms that were completed for the independent evaluator by consumers 1- 4 times per group whilst undertaking SPS services. Described at that time: their mental health and life experiences; and what would support or be a barrier to their recovery journey

A short open and closed ended questioned form completed for the organisation by consumers that described: their history; people and factors that may help them on their recovery journey; who they do not want involved in their recovery; signs when they know they are becoming unwell; and actions they can take to help themselves if they became or would prevent them from becoming unwell

A presentation developed by consumers describing their life experiences including challenges, changes, outcomes and benefits since undertaking the SPS service

${ }^{*} P C P$ - person centred planning ${ }^{* *}$ past experience- retrospective data $\mid{ }^{* *}$ current experience - occurring at the time of data collection.

consumers had undertaken the SPS service for approximately six months and had just begun to implement their action plans.

Consumers' demographic details indicated that the mean age of consumers was 46 years, with most being female
(56\%). One consumer was an Australian Aboriginal person with the remaining fifteen being of Caucasian ethnic backgrounds. The demographic details of consumers were gleaned from the data, limiting meaningful comparisons with national statistics to age factors only. The majority of 
Table 2 Number and percentage of data documents received and analysed

\begin{tabular}{|c|c|c|c|c|c|}
\hline \multicolumn{2}{|l|}{ Data sources and types of de-identified data } & \multicolumn{2}{|c|}{ Total \# received } & \multicolumn{2}{|c|}{ Percentage coded } \\
\hline Sources & Type of de-identified data & Documents & Pages & Documents & Pages \\
\hline \multirow{5}{*}{$\begin{array}{l}\text { Independent evaluator's data (documented } \\
\text { in in the past for PCP evaluation) }\end{array}$} & Consumer interviews summary (key points) & 3 & 3 & $100.00 \%$ & $100.00 \%$ \\
\hline & Consumer interviews & 3 & 35 & $66.66 \%$ & $62.85 \%$ \\
\hline & Reports & 3 & 37 & $100.00 \%$ & $100.00 \%$ \\
\hline & Staff interviews & 2 & 16 & $100.00 \%$ & $100.00 \%$ \\
\hline & Subtotal & 11 & 91 & $90.91 \%$ & $\mathbf{8 5 . 7 1} \%$ \\
\hline \multirow[t]{23}{*}{ The Guides' data (documented in the past) } & Personal learning & 2 & 2 & $100.00 \%$ & $100.00 \%$ \\
\hline & Organisational reports & 7 & 7 & $100.00 \%$ & $100.00 \%$ \\
\hline & Reflections on consumers progress & 292 & $292^{*}$ & $83.90 \%$ & $83.90 \%$ \\
\hline & Across four questions & & & & \\
\hline & a) What did I do* & & & & \\
\hline & b) What worked well* & & & & \\
\hline & c) What could I do differently* & & & & \\
\hline & d) Where to next* & & & & \\
\hline & Across the three groups & & & & \\
\hline & (4-7 times per group) & & & & \\
\hline & Reflections on four service phases & 53 & $53^{*}$ & $28.30 \%$ & $28.30 \%$ \\
\hline & Across four areas* & & & & \\
\hline & a) Selection phase & & & & \\
\hline & b) Administration of $\mathrm{PCP} * *$ & & & & \\
\hline & c) Development of AP*** & & & & \\
\hline & d) Implementation of AP & & & & \\
\hline & Four questions asked under each area & & & & \\
\hline & a) What did I do & & & & \\
\hline & b) What worked well & & & & \\
\hline & c) What could I do differently & & & & \\
\hline & d) Where to next & & & & \\
\hline & $\mathrm{PCP}$ reunion speeches & 4 & 9 & $100.00 \%$ & $100.00 \%$ \\
\hline & Subtotal & 358 & 363 & $76.26 \%$ & $76.58 \%$ \\
\hline \multirow[t]{6}{*}{ Consumers' data (documented in the past) } & Action plans & 16 & 23 & $100.00 \%$ & $100.00 \%$ \\
\hline & $\begin{array}{l}\text { Most important change (MIC) in my life } \\
\text { questionnaire (1-4 times per group) }\end{array}$ & 51 & 102 & $100.00 \%$ & $100.00 \%$ \\
\hline & Recovery questionnaire & 16 & 160 & $100.00 \%$ & $100.00 \%$ \\
\hline & $\mathrm{PCP}$ reunion speeches & 21 & 21 & $100.00 \%$ & $100.00 \%$ \\
\hline & Subtotal & 104 & 306 & $100.00 \%$ & $100.00 \%$ \\
\hline & Grand total & 473 & 760 & $81.81 \%$ & $\mathbf{8 7 . 1 0} \%$ \\
\hline
\end{tabular}

*Data only a quarter of a page $\mid{ }^{* *}$ Person centred planning $(P C P) \mid{ }^{* * *}$ Action plan (AP).

the consumers (87\%) were older in age (40 to 64 years) compared with national statistics that showed younger age groups (16 to 35 years) as having higher rates of mental disorders [32].

Of eleven consumers reporting educational experiences, seven had not completed secondary school. Five consumers, including two who had not completed secondary school, had completed tertiary education or vocational training at a later time. Five consumers were living with two mental illnesses. Diagnoses showed seven incidences of depressive and schizophrenic disorders, two incidences of bi-polar and generalized anxiety disorders, and an incidence of post-traumatic stress, delusional, and/or substance induced psychotic disorder. The types of disorders presenting in these consumers were consistent with the types of disorders shown in national 
statistics (e.g., affective, anxiety and/or substance abuse) [32]; however meaningful comparisons (e.g., prevalence by disorder or gender) were restricted. Of thirteen consumers reporting an occupational history, seven had worked in customer and/or service jobs, three had worked in transport, logistical and/or community service (voluntary and paid) jobs, and two had worked in government jobs. Roles occupied included frontline positions $(n=6)$, management positions in another's business $(n=$ 4) and/or in own business $(n=3)$, facilitator/coordinator positions $(n=2)$, and being a parent $(n=10)$, with some consumers holding multiple roles at a time (e.g., work, voluntary community service and parenting). At the time of the study, eight consumers were unemployed due to physical (e.g., back and respiratory) and/or mental health challenges, not having adequate skills and/or not being able secure work that suited their needs, and two were employed. The employment status of six consumers was unknown. Further, nine consumers were renting privately, seven were living in government subsidised housing, ten were sharing accommodation with children, partner and/ or family, while six were living alone. Within the limits of the data these consumers socio-economic experiences seemed comparable with national statistics, which suggest people living with a higher prevalence of mental illness experience socio-economic disadvantage; yet meaningful comparisons were restricted [32].

\section{Analysis}

Overall 473 documents (760 pages) of data, relating to the lived experiences of consumers, were received, uploaded and reviewed for coding using NVivo 9.2 (QSR International ${ }^{\odot}$, Victoria, Australia) qualitative software. In evaluating the SPS service to establish a pilot model for service practice, the data were analysed using an abbreviated grounded theory approach [33,34]. All types of data from all sources were coded to ensure that meanings within these were not missed; however, this resulted in higher percentage of documentation being coded until saturation of codes was achieved (89.05\%).

All of the consumers' data were coded; although saturation of overall codes was achieved at $79.81 \%$. Consumers' data were coded first to ensure that coding was not influenced by the analysis of data from the other sources. The Guides' data were then coded, followed by the independent evaluator's data until saturation was achieved (Table 2). The greatest amount of data was provided by consumers (285 pages of full writing and 21 pages of three quarter of a page of writing), followed by the independent evaluator (78 pages of full writing), and the Guides (24 pages of full writing, and 339 pages of one quarter page of writing). More detail on the volume and saturation of data may be found in Table 2 .
To support a grounded theory approach, the literature review for the study was not conducted until after the analysis was completed. Analysis involved coding data to capture meaning of experiences across physical, physiological, psychological, social, environmental and/or spiritual levels. This included using a systematic, open and focused, all-inclusive coding approach, allowing for the data to drive the development of codes, and sometimes be shared across codes, reflecting the multiple experiences associated with consumers' statements. During coding a constant comparative method was used. This ensured that the duplication of coding was minimised and kept the coder mindful of potential commonalities, differences, and relationships between codes, which were documented in memos and annotations.

Over ten weeks of coding, $10 \%$ of codes established at any point in time were randomly selected (four times) using the Excel spreadsheet random between function for quality checking by the chief investigator and an independent research officer of the project. The meaningfulness of statements within these codes was assessed, and the quality checkers and coder discussed and resolved any discrepancies by un-coding and/or re-coding statements to achieve consensus. Quality checking of a total of 26 codes and 240 statements showed an overall 96.25\% agreement between the coder and quality checkers. Over the next two weeks the coding was completed, reviewed and duplicated codes were merged together. Then, the resulting codes $(n=242)$ were quality checked a final time, and this achieved 99.6\% agreement. Discrepancies were resolved and the initial codes retained at the end of coding had achieved 100\% consensus.

These 242 initial codes were then reviewed, compared, and sorted several times using a bottom-up approach. This involved grouping highly related codes together to develop higher order categories. These categories were reviewed and grouped together to develop over-arching categories. All categories were mapped onto a chart using Microsoft VISIO. These maps, categorical information and notes documented in memos and annotations were reviewed and compared. This enabled for commonalities, differences, and relationships to guide the final positioning of categories and develop the preliminary pilot model of SPS service practice. This preliminary model was then reviewed by the chief investigator, and a reference group involving a consumer living with mental illness, the independent evaluator, a consultant who had administered the PCP process, and three managers who worked in three different mental health services. No changes were required. Thus, the preliminary pilot model of service practice was finalised and retained.

The section of the final pilot model of service practice that related to the aim of this study showed a four tiered categorical structure. This structure included four over-arching 
categories (first tier) within which a varied number of sub-categories (second, third or fourth tiers) had been established from the initial codes. In preparation for writing, the sub-categories at varied levels were then read closely to gain insight into the particular meaning of the statements sitting within them. These meanings were documented as 'data descriptors' onto Excel spreadsheets, enabling the key meanings of all statements within categories to be known and articulated in the results.

\section{Ethics approval}

Ethical approval (OTSW-15-2011) was gained from the Office of Research and Development Human Research Ethics Committee at Curtin University in WA.

\section{Results}

Overall, the results revealed that consumers of the SPS service encountered four primary recovery experiences. A total of 5,185 descriptors, developed on 3,898 statements, were shared across four primary recovery experiences (Figure 1).

These results are reported at a group level, rather than case level, using the terms that are defined in Table 3.

\section{Over-arching category 1 - a greater sense of empowerment}

A total of 229 descriptors suggested that consumers (denoted C) gained a greater sense of empowerment. These descriptors were developed on 166 statements from two sub-categories (second tier) that underpinned over-arching category 1 . The two sub-categories included: 1) desire for empowerment; and 2) change experienced. The descriptors developed from these indicated that consumers desired empowerment, further emphasised by the Guides. The data also showed that these desires were met with consumers being supported by the Guides to overcome challenges.

Some descriptors $(n=55)$ from consumers' action plans, questionnaires and speeches and the independent evaluator's consumer interview and evaluation report data showed that all consumers, at varied levels, wanted more independence, freedom, control and choice, and/or to decrease reliance on others, as highlighted:

\section{“...become more independent.” (C1) \\ "Complete freedom from input from services...more control ..." (C2) \\ “...not have to rely on others." (C12)}

Some descriptors $(n=53)$ from the Guides' (denoted by $G$ ) learning, reflections and speeches and the independent evaluator's staff interview (denoted IE S INT) and evaluation report data indicated that the Guides desired for and engaged actions to enable consumers' empowerment. The Guides' practical and emotional support provided sensitively and responsively facilitated consumers' self-direction. The Guides did less for consumers, while providing support and encouragement to them to self-direct, and facilitating their connections with individuals and groups in the community, as highlighted:

“...[consumers]...encouraged to be more self-driven...do more of their own research...meant they had greater ownership over their action plan" (IE S INT)

"...encouraged them to make their own way to the sessions... bring their own support people rather than relying on support workers” (G)

\section{Percentage of data emerging across the consumers' recovery experiences}

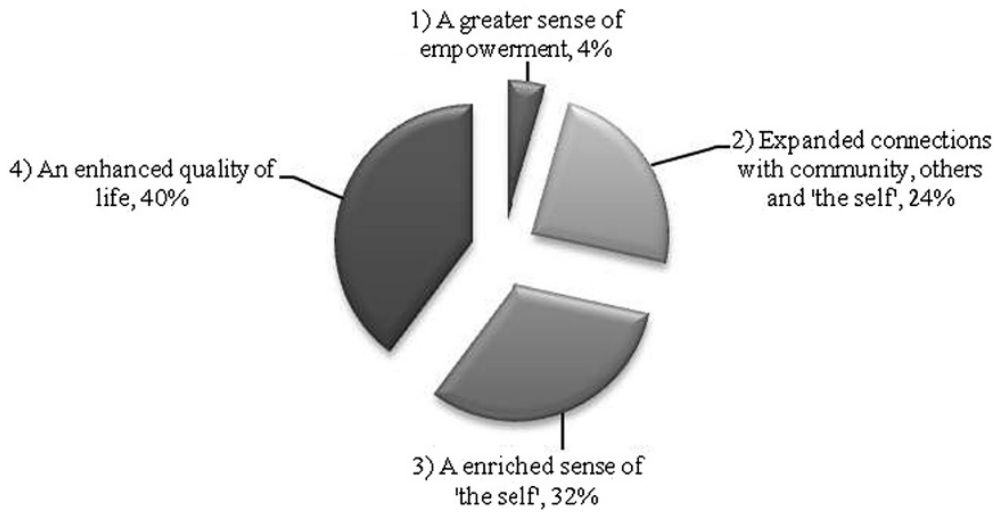

Figure 1 The distribution of 5,185 descriptors across consumers' recovery experiences. 
Table 3 Defining the amount of consumers reported throughout the results section

\begin{tabular}{ll}
\hline Amount of consumers & Number of consumers \\
\hline All & 16 \\
Most & $15-11$ \\
Many & $10-6$ \\
Some/few & $5-1$ \\
\hline
\end{tabular}

"Spoke to Consumer 5 about me [the Guide] exiting out of supporting him" (G)

"Left Consumer 6 to research prices for items on action plan" (G)

"Encouraged Consumer 8 to problem-solve...come up with...options...did not jump in and fix..." (G)

This support enabled consumers' autonomy, independence, freedom in choice and decision-making, and learning of new behaviour and ways of thinking, as discussed elsewhere [17].

Many descriptors $(n=121)$ from consumers' action plans, questionnaires and speeches and the Guides' reflections showed that consumers gained a greater sense of empowerment while undertaking the SPS service. This seemed intrinsically related to them having access to individualised funds and full control over all aspects of their recovery journey, which supported them to identify their dreams, develop recovery goals and implement action plans, and experience freedom in their choice and decision-making, discussed further elsewhere [17]. Many consumers expanded their connections with individuals and/or community groups, known or unknown to them, and enhanced their awareness, skills and knowledge, and/ or self-reliance (discussed in more detail later). This meant that most consumers' reliance on others was reduced to varied levels. A few consumers were quite autonomous in their self-direction early in their undertaking of the SPS service; yet some consumers needed more consistent and longer amounts of support to manage self and/or service related challenges. In the process of self-directing all consumers encountered new (e.g., self-confidence, motivation, self-worth and hope) and/or enhanced (e.g., control, independence and positive) positive emotional experiences, as highlighted:

\section{"It takes a bit of getting used to all this freedom of choice... really feel like I am listened to and supported with what I want to achieve." (C1)}

"I am a person with rights...can speak freely... deserve respect and expect it...can hold my head high and look anyone in the eye." (C3) "...made me realise that I can do things like improve my confidence, self-esteem...do things I was unsure about..." (C12)

Some consumers were optimistic, positive, motivated and gained confidence early while undertaking the PCP process. Many consumers developed hopefulness, confidence, optimism and motivation as they developed, implemented, and/or achieved their action plan recovery goals. A few consumers struggled with their motivation due to personal (e.g., physical health or family) and/or service (e.g., being ready to implement their action plans but having to wait for access to individualised funds, struggling to manage their individualised funds, or feeling pressured to achieve goals within specified time limits) related challenges, as highlighted:

"Motivation is not good at moment; Finding it difficult to meet my goals to make the positive changes in my life" (C3)

"My motivation [may get in the way]...feel fatigued all the time;" (C4)

These consumers preserved working with the Guides to resolve their respective challenges, and in doing so they made progress in their recovery journey. A consumer, although making progress, made less progress than most others, having consistently struggled with implementing the action plan; however, within the limits of the data the clarification of this experience was restricted. Overall, consumers while undertaking the SPS service showed a desire for gaining and, at varied levels, achieved a greater sense of empowerment.

Over-arching category 2 - expanded connections with the community, other individuals and 'the self'

A total of 1,245 descriptors indicated that consumers expanded their connections. These descriptors were developed on 1,046 statements from sub-categories (second and third tiers), which over-arching category 2 was developed on. Second tier sub-categories included desires and outcomes and these related to third tier sub-categories that included wanting to and expanding connections with community, others and 'the self'. These were developed from fourth tier sub-categories that related to: 1) engagement of community groups; 2) relationships with partner, family, friends, known professionals and/or new people; 3 ) emotional experiences; and 4) improved relationships.

Some descriptors $(n=114)$ from consumers' action plans, questionnaires and speeches data suggested that consumers wanted involvement in community services and/or to make a contribution to the community. A few descriptors $(n=7)$ 
indicated that the Guides also wanted to expand connections with community to enhance consumers' community connections. Some descriptors $(n=92)$ indicated that consumers had joined community groups for varied purposes. Many consumers had used dating, social and/or health and fitness groups for social, recreational and/or health and fitness purposes. Many consumers had also used professional groups, attending courses (e.g., computer, photography, parenting, assertiveness, and/or communication) to improve their skills, interpersonal relationships abilities, health and wellbeing, and/or employment opportunities. Some consumers had engaged individuals (e.g., personal trainer, music tutor, experts in financial management, career development or legal matters, driving instructor, doctor, or counsellor) and/or family services (e.g., family therapy) to progress their recovery. These statements highlight such experiences:

"...the teacher...really helped me build my confidence...was really shocked when [the teacher] told me I was a natural." (C1)

"The first thing we did was get a computer and sign up for the net. It has opened our world..." (C3)

"...acquire[d] a laptop...to keep up with my work...stay in touch with people, friends in other countries..." (C5)

“...through...photography group I'm learning more new skills...interacting with new people...” (C6)

Many descriptors $(n=246)$ from consumers' action plans, questionnaires and speeches, the Guides' learning, reflections, meeting minutes and speeches, and the independent evaluator's interview and evaluation report data showed most consumers wanted to enhance their connections with others, in particular relationships with and/or the life experiences of their family members. Many consumers also wanted to strengthen their existing connections with friends and known professionals or expand their connections by meeting new people and widening friendship circles. A few consumers wanted to become involved in helping people less fortunate and unknown to them. Many descriptors $(n=294)$ also showed that in their recovery, most consumers connected with family, friends, peers, and familiar and new people for social, recreational, health and wellbeing and/or professional reasons. Most consumers also strengthened their personal networks through increased socialising with known friends and/or family, or newly made friends including peers who were using the same SPS service. Further, many consumers increased contact with familiar professionals (e.g., support workers, carers, and medical professionals) or new professionals (e.g., tutors, teachers, trainers, and health care and other specialist service individuals and/or organisations). Some descriptors $(n=77)$ indicated that many consumers also experienced improved relationships, mostly with family and, for some consumers, with peers and work colleagues.

In expanding connections, some descriptors $(n=34)$ showed that consumers encountered positive emotional experiences, at varied levels. These encounters appeased the initial negative feelings (e.g., cynical, hesitant, anxious, and/or distrustful) that some consumers had experienced prior to or at the time they were starting the SPS service, as highlighted:

“... have problems with trusting people...[the Guide] helped me...when I told them.... said well if that had of happened to them they would have done the same thing... made me feel better...I really like [that] they... treat me like a person and tell me all the things I can achieve...spent a lot of years being told what I can't do but I am starting to see all the things I can achieve and it's not impossible." (C1)

"At first I found it very strange... hard to understand how I could see a positive future for myself...I was very lonely and isolated and had no purpose...nothing good in my life...was waiting to die. Now I feel like I have a purpose, a journey to partake... looking forward to joining the gym and getting fit, getting back into my art, making friends and being connected in my community... eventually being able to give back to my community (C14)

Further, some other descriptors $(n=65)$ from consumers' recovery questionnaires and speeches, the Guides' learning and reflections, and the independent evaluator's interview and evaluation report data showed that all consumers experienced positive emotional encounters when expanding connections within the community and with others. They experienced (one or more) of the following including feeling supported, encouraged, guided, motivated, positive, happy, confident, empowered, free to trust and be open without fear of judgement, free to be flexible, valued, strong, and less isolated. For some consumers, these emotional experiences were new and/or affirming of not frequently felt feelings. These emotional experiences seemed to enhance consumers' self-knowledge and/or knowledge about themselves in relation to others, as highlighted:

"... will finish a massage course...opened me up to doing an accredited course... with each course I accept myself a little more and think maybe one day I'll... have had some amazing opportunities..." (C3)

"...social contacts that I have made since...have... encouraged me to stay strong... keep believing in myself and what I am doing..." (C7) 
Most of the descriptors $(n=316)$ from consumers' action plans, MIC questionnaires and speeches, the Guides' reflections, and the independent evaluator's interview and evaluation report data revealed that most consumers, at varied levels, wanted to enhance connections with 'the self', and this was achieved through improved selfreflection and awareness (fully discussed in the next overarching category), as highlighted:

“...this experience has changed my outlook, wellbeing... helped me to take another look at life and living and join and participate in life... instead of hiding from it..." (C6)

"...has made me more aware... that I have all the abilities... without... previous self-doubts and worries." (C7)

"I could see others seeing me in a different light to myself...I slowly started to believe in myself and see myself as worthy." (C14)

Overall, consumers achieved their desires to expand their connections with the community, other individuals, and 'the self', at varied levels, while using the SPS service. While expanding their connections, most consumers seemed to enhance their cognitive and emotional awareness and self-reliance, and reduce their isolation.

\section{Over-arching category 3 - an enriched sense of 'the self'}

A total of 1,649 descriptors indicated that consumers wanted to enhance their occupational experiences and wellbeing, and that they achieved this in their recovery experiences. These descriptors were developed on 1,346 statements from sub-categories (second and third tier, respectively) that underpinned over-arching category 3. Second tier sub-categories included 1) occupational aspects of 'the self'; 2) wellbeing; 3) discovering 'the self'; 4) increasing self-belief; and 5) improving vitality. These were developed on third tier sub-categories based on a range of consumers' desires and achievements. Desires included wanting to: 1) improve aspects of the occupational self; 2) improve psychological and physical health; 3) try new things for themselves; 4) increase their selfconfidence and feel better about them selves; and 5) improve self-motivation, activity and/or energy. Their achievements included them: 1) developing their occupational capacity and/or acquiring work; 2) improving insight, thoughts and/or emotions and behaviours; 3) discovering positive aspects about themselves; 4) experiencing enhanced self-belief; and 5) feeling motivated from being able to contribute, having a sense of purpose and direction, and future plans and hopes.

Many descriptors $(n=288)$ from consumers' action plans, questionnaires and speeches, the Guides' reflections, meeting minutes and speeches, and the independent evaluator's interview and evaluation report data showed that most consumers wanted better occupational experiences as this would enhance their sense of wellbeing. They wanted to find more meaningful, satisfying, flexible, and predominantly part-time employment that suited their overall lifestyle demands and would enable them to improve their financial security and/or make contributions to their community, as highlighted:

\section{"Work in a job that I dictate my hours of work, with flexibility when needed." (C2) \\ "Meaningful employment." (C5) \\ "Working helping others." (C9) \\ "Up-skilling myself to re-enter the workforce." (C13) \\ "Have a job that is financially rewarding." (C15)}

While undertaking the SPS service, many consumers engaged in one or more actions to secure desired employment. Some consumers sought job and career counselling, searched for desired jobs, completed job applications, and attended selection interviews. They also researched job related requirements to proactively develop these (e.g., computer, artistic, and photography skills, and health and fitness) or attain licences or certificates with the intention of applying for desired employment in the future, as highlighted:

“...do some courses...obtain different licenses...striving

to return to the workforce..." (C6)

"...work in a good job [even] if that means studying." (C16)

"My goal for the end of this year is to apply for the army [has been to a defence force assessment]." (C8)

Some consumers procured equipment or services that assisted them (e.g., computer, Internet access kitchen knives, and a bicycle). Three consumers secured employment in jobs that they valued and planned to continue with.

A few consumers also wanted to improve their parenting and family occupational experience:

“...going to counselling to sort out some family

issues." (C3)

“...still over-commit...endeavour to temper my motivation to work with my devotion as...carer to my four children aged fifteen and under...." (C5) 
“... I am going to go to a parenting course to see if I can improve my parenting, understand my kids better...do a better job." (C10)

These consumers experienced improved parenting and family interpersonal encounters while using services, and this seemed related to their enhanced self-awareness and relationships, and parenting capabilities, as highlighted:

"I now feel [that I am] acceptable...my dreams...my boys' dreams may be accomplishable." (C3)

"...has made my life more fine-tuned... have a greater resolve...ability to see things through....the [service] has put me in a much better position than...one year ago." (C5)

"...has changed my whole style of parenting...more aware...that I have all the abilities to raise a wonderful little girl..." (C7)

“...I feel more independent...confident...am being a good mum...have more contact with... family that I didn't do much of before the [service]." (C10)

Many descriptors $(n=292)$ from consumers' action plans and questionnaire data showed that all consumers wanted to improve their physical and/or psychological wellbeing. Consumers mostly reported wanting to improve their physical health, including body weight, feelings of sickness, lethargy and/or fatigue, and pain from having a broken limb, back injury and/or surgery. Some consumers wanted to manage their mental health better. These experiences were as highlighted:

"...to be able to accept and acknowledge my creativity and artistic talents." (C11)

“...get on top of anxiety attacks..." (C12)

"...get fit and strengthen back; improve fitness and lose weight." (C15)

Consumers' action plans, questionnaires and speeches, the Guides' reflection and speeches, and the independent evaluator's interview and evaluation report data revealed that many consumers joined groups (e.g., gymnasium or health and fitness clubs) and/or engaged in fitness (e.g., cycling, walking, swimming, and horse-riding) activities to improve their physical health. Many consumers also engaged in wellbeing practices (e.g., counselling, better eating, helpful thinking, self-development courses, and social and recreational groups). In these encounters most consumers experienced improvement in one or more physical and/or psychological aspect, at varied levels, as highlighted:

"...started to swim...made me feel awesome and very positive." (C9)

“...take aquatics...body balance...complements my physiotherapy...helps me deal with my back pain... more able to cope with the side effects of... medicine... muscle stiffness...trying to eat healthily... become food aware." (C4)

“... I have made progress with my depression... used to be bad." (C1)

Many descriptors $(n=379)$ from consumers' action plans, recovery questionnaires and speeches, the Guides' reflections and speeches, and the independent evaluator's interview and evaluation report data showed that all consumers, at varied levels, experienced self-discovery. Through selfdirecting, and developing and implementing action plans, consumers were required to self-reflect, address, and work through challenges to try new behaviour and/or ways of thinking, discussed further elsewhere [17]. In this journey, and through intrapersonal encounters, consumers discovered and became more aware of their strengths, challenges, potential and capability, and value and worth.

Some descriptors $(n=101)$ indicated that most consumers experienced improved wellbeing from enhancing connections in the community and with others, reducing isolation, and encountering new and positive emotional experiences that enabled them to gain new understanding and growth, as discussed in the previous categories and in more detail in another study [17]. Wellbeing was also experienced from some consumers managing unhelpful behaviours in better ways (e.g., not acting out in anger, becoming more organised by creating schedules and/or routines and/or asserting their needs to set clear boundaries). Also, new or irregularly experienced positive emotional encounters with others (e.g., service staff, peers, and community professionals or groups) that provided praise, encouragement, and validated their self-worth influenced emotional change in consumers. Consumers' wellbeing was supported by increased self-confidence, happiness, optimism, motivation, and/or the gaining of hope for the future from having a sense of purpose and direction, as highlighted:

“...am doing really well with my anger...controlling my anger much better." (C1)

"This...has been the most pro-active, self-determining journey of the last 35 years... I have struggled with it and loved it..." (C5) 
"...have more confidence in myself... started to change my life and the way I see and do things, all for the better...given me the ability and enthusiasm." (C6)

"Relationship with everyone at $[\mathrm{PCP}]$ gave me a reason to come back, they were friendly... very helpful... was a new experience for me that I haven't been in before." (C8)

"...realised...I can have a future...reach my goals... have what I... want out of life." (C13)

Some descriptors $(n=194)$ from consumers' action plans, questionnaires and speeches, the Guides' reflection and speeches, and the independent evaluator's interview and evaluation report data suggested that most consumers experienced, at varied levels, an increased sense of belief in 'the self', as highlighted:

"...everything in my life is just better, have a direction for my future...feel more confident, happy and really excited about my future" (C8)

"...made me realise...I can do things like improve my confidence, self-esteem and do things I was unsure about and are now working on." (C12)

\section{"Now I really feel that I can be a useful person in the} community." (C14)

Consumers' increased self-belief seemed related to other experiences they had encountered (e.g., gaining of a sense of empowerment, expanding connections with themselves, others and the community, self-discovering, and experiencing enhanced wellbeing). Increased self-belief also seemed related to their consistent encounters of positive emotional interactions with peers, the Guides and individuals and groups in the community, discussed earlier and fully elsewhere [17].

Most descriptors $(n=395)$ from consumers' questionnaires and speeches, the Guides' reflections, speeches and meeting minutes, and the independent evaluator's interview and evaluation report data showed that all consumers had experienced enhanced vitality, at varied levels. Some consumers had struggled with becoming motivated and/or experienced intermittent wavering motivation and increased stress while undertaking the SPS service. This was related to not having access to individualised funds at a time they were ready to implement their action plan, not knowing how to manage funds using a process that enabled reconciliation of expenditure, experiencing stress from developing new ways of thinking or actions, choosing stressful recovery goals (e.g., study), and/or feeling pressure to implement action plans within specified times. Despite these challenges, some of the consumers wanted to improve their motivation. Most consumers' vitality seemed to increase while they were using the SPS service. This was seen in their commitment to planning, implementing, working through and, for most, resolving challenges to partially or fully accomplish their recovery goals. Vitality was also enhanced from encountering positive emotional experiences through interpersonal interactions with others, succeeding and achieving recovery goals, and gaining a sense of direction, purpose, and hope for the future, as highlighted:

$$
\begin{aligned}
& \text { “...feel... worse off because...this is too much...at the } \\
& \text { moment...but...keep on thinking December [when } \\
& \text { course ends] comes along I will be a lot better." (C2) } \\
& \text { "... has motivated me to try to get ahead in life." (C13) } \\
& \text { "...isn't easy being faced with a different aspect on ways } \\
& \text { one can make a difference in ones' life... always up for } \\
& \text { the challenge... willing to give it my best shot." (C11) }
\end{aligned}
$$

\section{Over-arching category 4 - an enhanced quality of life}

A total 2,062 descriptors suggested consumers experienced an enhanced quality of life while undertaking the SPS service. These descriptors were developed on 1,340 statements from sub-categories (second, third and fourth tier) that underpinned over-arching category 4 . One second tier sub-category included consumers' experience of challenges. This was developed from third tier subcategories that included: 1) self-related challenges; 2) resource related challenges; and 3) relationships related challenges. Another second tier sub-category included discovering a better quality of life. This was developed from third tier sub-categories that included: 1) taking actions to achieve; 2) achieving, succeeding, accomplishing, and significant encounters; and 3) experiences after SPS services. A third second tier subcategory included having hope for a better future from achieving their recovery goals. This was developed from third tier sub-categories including: 1) achieving, succeeding, accomplishing, and significant encounters; 2) hopes, aspirations and wishes; and 3) feeling life is good or very good. A fourth second tier sub-category included improving access to resources, and this was underpinned by third tier sub-categories that included improving: 1) income; 2) home-ware; 3) technology; and/or 4) assets.

Although a few consumers reported overall good early and adult life experiences, many reported adversity in their life, within which some had experienced happy encounters (Table 4).

A few descriptors $(n=36)$ from consumers' recovery questionnaires and speeches, and the individual evaluator's consumer interview and evaluation report data showed 
Table 4 Consumers' life experiences in childhood and/or adulthood prior to involvement in the SPS service

Overall challenges as a child: abuse; neglect; loss of parent (e.g., death and/or marital separation); loss of a sibling (e.g., death, marital separation, rejected from home or institutionalised care); and/or loss of health (e.g., accident, self-harm and/or substance abuse)

Overall challenges as an adult: exposure to domestic violence; loss of parent/s (e.g., death); partner/s (e.g., marital separation/s), and/or child (e.g., custody or running away); and loss of physical health (e.g., emphysema, tumours and severe back problems)

\section{Happy experiences}

Happy experiences encountered within diversity (e.g., success in school, success in managing adverse early life experiences and/or mental illness, and/or having children that they love)

Overall okay, happy and/or loving upbringing and home

$n=10(63 \%)$

\section{Adverse experiences}

$\begin{array}{lc}\text { Abuse and/or neglect } & n=8(50 \%) \\ \text { Parental loss } & n=8(50 \%) \\ \text { Physical health challenges } & n=8(50 \%) \\ \text { Child loss } & n=7(44 \%) \\ \text { Unhappy and/or unsafe home } & n=7(44 \%) \\ \text { Institutionalised care } & n=5(31 \%)\end{array}$

that, in the past, all consumers had experienced one or several adverse experiences as a child and/or adult, as seen in Table 4. They had also encountered some good experiences. These included having access to supportive relationships at different times, success in sport and/or work occupations in their youth and/or adulthood, and/or access to higher educational opportunities.

At the time they were starting the SPS service, consumers' action plans, questionnaires and speeches, the Guides' learning, reflections, meeting minutes and speeches, and the independent evaluator's interview and evaluation report data showed that consumers were experiencing some or many challenges across many or all aspects of their life (Table 5); however, while undertaking the SPS service these challenges or their impact became eliminated or reduced by consumers using better management practices.

Most descriptors relating to current challenges, as noted previously, reflected self-related $(n=653)$, resource $(n=188)$

\section{Table 5 Consumers' challenges experienced at the start of, during, or after their undertaking of the SPS service}

\begin{tabular}{|c|c|c|}
\hline Aspect of life & Challenges reported at the start of the SPS service & Change experienced during and/or at the end of the SPS service \\
\hline Behavioural & Self-isolating, unhelpful, and/or avoidance behaviour & $\begin{array}{l}\text { Unhelpful behaviour was managed better and/or reduced, and } \\
\text { helpful behavior was increased }\end{array}$ \\
\hline Health & $\begin{array}{l}\text { Consistent worry and/or having to manage negative } \\
\text { impacts of physical/mental health issues and/or } \\
\text { medication }\end{array}$ & $\begin{array}{l}\text { Improved physical/mental health problems from better management } \\
\text { and/or perspectives }\end{array}$ \\
\hline $\begin{array}{l}\text { Emotional } \\
\text { and/or } \\
\text { cognitive }\end{array}$ & $\begin{array}{l}\text { Constant experience of few or many negative } \\
\text { emotions (e.g., worry, anxiety, fear, stress, distrust, } \\
\text { hopelessness, helplessness, shame and guilt, } \\
\text { worthlessness, living without hope/direction, } \\
\text { poor self-esteem or confidence, sadness, } \\
\text { demotivation, and powerlessness) }\end{array}$ & $\begin{array}{l}\text { Improved attitudes and emotions from gaining a more positive outlook } \\
\text { and/or emotions about 'the self', significant others and/or their future }\end{array}$ \\
\hline Resources & $\begin{array}{l}\text { Had little/no adequate financial resources. This } \\
\text { included limited access to resources to engage social } \\
\text { activities, pay bills and fees, and support their family } \\
\text { needs. This also included limited opportunity to } \\
\text { improve assets, work in jobs that paid adequately } \\
\text { and/or met the lifestyle needs }\end{array}$ & $\begin{array}{l}\text { Engaged services to develop skills, knowledge and/or 'the self', } \\
\text { acquired resources that optimised their chance to work towards } \\
\text { and/or attain satisfying and/or adequately paid work, and/or welcomed } \\
\text { new opportunities to grow and develop personally and encounter } \\
\text { positive experiences }\end{array}$ \\
\hline $\begin{array}{l}\text { Social and } \\
\text { relationship }\end{array}$ & $\begin{array}{l}\text { Wanted to improve their quality of life and/or relationships } \\
\text { with the family, enhance friendships with existing } \\
\text { and/or new people, and expand connections with the } \\
\text { community }\end{array}$ & $\begin{array}{l}\text { Improved relationships with family, familiar others, and the community, } \\
\text { and encountered positive experiences from stronger connections that } \\
\text { broadened their networks }\end{array}$ \\
\hline Independence & $\begin{array}{l}\text { Wanted to increase their independence, freedom, control, } \\
\text { and choices, and decrease reliance on others and/or services }\end{array}$ & $\begin{array}{l}\text { Gained a sense of empowerment, strength, control, and increased } \\
\text { self-confidence and belief }\end{array}$ \\
\hline
\end{tabular}


and relationship $(n=11)$ challenges. Self-related challenges included unhelpful avoidance coping (e.g., procrastination, side-tracking, withdrawing, and isolating), medication use, organisational and time management practices, substance use, and lifestyle practices (e.g., neglecting or not asserting own needs, sleeping all day, not eating well or properly, and being highly dependent on services), as highlighted:

\section{"...concerned about increase in...buying of no doze and energy drinks" (G)}

\section{"...I can get myself into bad situations when I get} really angry..." (C1)

"...lose motivation and isolate myself." (C4)

“...still not able to take her medications..." (G)

Self-related challenges also reflected the relentless demand to manage the impact of physical and psychological health problems and issues. Some consumers were managing pain, illness and/or injury to their body and/or organs, while living with the knowledge that there was little potential for full physical health recovery. A few consumers were managing the side-effects of medication or learning to use medication properly. Some consumers were managing relentless worry about the health problems of a significant other. Further, the data showed that all consumers frequently experienced demand to manage negative feelings in relation to themselves, their relationships with other people, and/or life in general, as highlighted in Table 4 and in these statements:

"...life was about surviving day to day...never looked at my future...didn't think I had one or...one I wanted" (C1)

"Feeling down; negative; my life is boring" (C10)

"Lack of self-worth...confidence..." (C11)

A few additional descriptors $(n=42)$ reflected this demand in some consumers' challenge to manage negative, sometimes overwhelming, emotions. This included feeling anxiety, fear or discomfort, hesitation, and/or cynicism from having committed to undertake the SPS service, as highlighted:

"...very unsure of...[SPS service].. don't like ...crowds... didn't...know what it was...about or what to expect" (C6)

"...was...hesitant....thought this was just going to be the same as other services..." (C9)

"Initially...found it...bewildering, uncomfortable, confrontational, emotional...painful..." (C11)
Resource related challenges, experienced by all consumers, reflected that limited access to finances was the most predominant issue. This restricted consumers' access to basic resources including household goods (e.g., kitchen knives, TV antenna, fridge, camera, or a computer) and a safe home. It also reduced their chance to socialise (e.g., go out for a coffee or meal), pay bills or fees, or give their children the opportunity to engage in sports and recreational activities. No consumer had experienced an opportunity to build financial security (e.g., own their own home or car, upgrade their home to have basic goods, and/or have access to a safe and reliable car). Another resource challenge experienced by many consumers included the lack of time to manage general life demands, health problems, and quality time with their partner, children, or grandchildren to strengthen relationships and/or resolve conflict. Other resource challenges included lack of access to employment that provided an adequate income and a solid friendship network from not having access to enough friends.

Many descriptors $(n=772)$ from consumers' action plans, questionnaires and speeches, the Guides' learning, meeting minutes and reflections and the independent evaluator's interview and evaluation report data suggested that all consumers experienced change from discovering a better quality of life. This occurred at varied levels and related to them better managing and/or resolving some or most of their challenges. The negative feelings that some consumers felt at the beginning of the SPS service dissolved and were replaced by feelings of excitement, inspiration and motivation. Positive experiences (e.g., encountering a continuous and supported process, partially or wholly achieving their recovery goals, having control over all aspects of their recovery journey, engaging more in relationships with known and/or new people, and having access to recovery resources) facilitated their learning and application of new and helpful behaviours and ways of thinking.

Consumers' and the Guides' speeches, and the independent evaluator's consumer interview and evaluation report data indicated that consumers, while self-directing the SPS service experienced change and growth. In this, they learned, developed, changed, and gained insight into what was working for them and/or what they needed to change (e.g., unhelpful thinking or behaviour), which enabled them to partially or wholly achieve their recovery goals, as fully discussed elsewhere [17]. A few consumers were self-directing services mostly by themselves about a quarter or mid-way into their undertaking of the SPS service. Most consumers were solely self-directing their services nearing their completion of the SPS service. All consumers, at varied levels, were committed to selfdirecting and implementing their action plans; although one consumer, despite making progress, required consistent support from the Guides to manage unhelpful 
behaviours that led to side-tracking or stopping the full implementation of the action plan. Within the limits of the data this experience could not be explored further.

Consumers' action plans, recovery questionnaires and speeches, the Guides' learning, reflections and speeches, and the independent evaluator's interview and evaluation report data showed that all consumers, at varied levels, experienced enhanced self-awareness, which provided most of them clarity in understanding their journey in recovery and life. This also gave them direction and a sense of purpose that added to and had a profound impact on their quality of life, as highlighted:

"...main thing I got out of doing [SPS service] is that it is ok to set goals and dreams" (C10)

"I am now doing things that I previously would not be doing...have more confidence in myself...started to change my life and the way I see and do things, all for the better." (C6)

Many descriptors $(n=360)$ suggested that all consumers gained hope for their future while using the SPS service. This was seen in most consumers' desires to maintain, or continue to make new connections with others, engage more activities, maintain improved relationships, continue to work towards improving their physical and/or psychological health and wellbeing using better management and/or lifestyle practices (e.g., eating better), and/or secure employment that suited their needs and provided them access to resources (as discussed earlier). Many consumers wanted to continue to improve themselves (e.g., behaviour, cognition, confidence, skills, attitudes, and view of self) and/or maintain the lifestyle (e.g., continue with hobbies and recreational activities) they wanted. Some consumers wanted to make contributions to the community to help others less fortunate than them. Most consumers also wanted to pursue their direction, purpose and meaning in life and maintain their freedom, independence, and control of their life and recovery journey.

"I am going to be use some of my money to....see a private psychiatrist to help me..." (C1)

“...do...courses...obtain different licenses...am striving to return to the workforce" (C6)

"Most of all for me I wanted to live again...for me" (C7)

"Everything in my life is just better, have a direction for my future...feel more confident, happy and really excited about my future" (C8)
More descriptors $(n=32)$, additional to the 5,185 descriptors discussed so far, from consumers' questionnaires and speeches, the Guides' learning, reflections, meeting minutes and speeches, and individual evaluator's consumer interview report data suggested that consumers' family members also experienced positive rollon effects from their undertaking of the SPS service. A few family members, from sharing their consumers' recovery experiences, were inspired and motivated to undertake similar activities (e.g., study, learn to drive and get their licence). Some consumers used their individualised funds to provide family members access to resources (e.g., counselling, carer, sports, and household equipment) that these members may otherwise not have had access to. While undertaking the SPS service consumers' relationships with their family members, alongside friends, work, and familiar others improved, and as reported by consumers, this seemed to enhance the quality of life experiences for those experiencing the improvement, as highlighted:

“...mother even stays for 2 days each fortnight... wasn't possible before..." (C3)

"...family and I have achieved much this year...no domestic support or paid companionship...we now pitch in together and get the housework done." (C5) “...shown me a better way to cope with problems
with...family and friends." (C7)

"...funding has helped [children] enrol in netball... soccer and [purchase]...equipment for these sports... they are having fun, being active and having contact with other kids." (C10)

In summary, the data from consumers, the Guides, and the independent evaluator, indicated that consumers with mental illness undertaking the SPS service encountered four primary recovery experiences. These included consumers gaining a greater sense of empowerment, expanded connections with community, others and 'the self', an enriched sense of 'the self', and an enhanced quality of life. Further, the results showed that some family members of consumers also benefitted.

Although the four primary recovery experiences were reported independently, the results showed that these overarching categories (first tier) and related sub-categories (second, third and or fourth tiers) were interdependent. That is, a change in one area (e.g., empowerment) influenced and/or was influenced by changes in another area (e.g., expanding connections). Together, these results suggested that consumers' personal recovery differed across individuals. Some experienced varied challenges; yet most experienced change and had started to build a meaningful and satisfying life. 


\section{Discussion}

These results, although using data collected in the past rather than in real-time data as was done in other studies, resonate with the results of previous research. The results suggest that these consumers' experience of greater responsibility, accountability and/or motivation supported their learning, and this evolved while undertaking SPS services. Their learning was enhanced from being supported to define, research, source, procure, action, and/or achieve their recovery goals and journey $[8,9,11]$. These consumers resolved challenges through trial and error, at varied levels, using the support of shared management and person-centred relationships with the Guides. These relationships gave consumers individually tailored, timely and meaningful support, discussed in more detail in another study [17]. As in other studies, in this study most consumers experienced more self-reliance and self-direction, feelings of confidence and competence, and a sense of empowerment, at varied levels $[2,8,11]$. They also expanded and kept their connections with community and others. This enhanced their opportunity to secure employment and/or develop their skills and knowledge through university or other training, and improved their daily living practices $[8,9,18,21,26]$.

Consumers also experienced positive emotional encounters while undertaking SPS services. This seemed to enhance their motivation, behavioural, cognitive and emotional growth, future planning and hope, and their sense of 'the self' and quality of life $[9,11,21,30]$. Consumers, from being placed in the centre of services and provided control over choices and decisions in their personal recovery journey, and flexibility to work at a pace that suited them, experienced legitimacy to dream, desire, request and take action for 'the self' [8,9,17-19,21]. In this, they encountered new and corrective emotional experiences that supported most consumers to experience 'the self', others and their relationships with others and the wider community (e.g., health services) in different and helpful ways [17].

These results, like other research, suggested that the SPS service offered consumers timely access to individualised funds and high quality shared management and person-centred services, enabling them to encounter positive and emotionally corrective experiences and achieve personal recovery goals $[8,9,18,21,26]$. This enabled these consumers' self-direction of services, change and growth. Most of these consumers from undertaking the SPS service had some or most of their desires and needs met in meaningful and effective ways, leading to improved recovery and life experiences.

Despite these positive outcomes it is important to recognise that there were individual differences in consumers' experiences. All consumers' personal recovery journeys differed. A consumer, although experiencing some progress in the recovery experiences, struggled to move forward in the journey as much as many of the other consumers. Further, some consumers struggled with their motivation to implement their action plans from time to time and/or spend their individualised funds appropriately, although they successfully worked closely with the Guides to overcome these challenges. As noted by others, such individual differences are expected [15]; however, in this study further exploration of these differences was limited, being contained to available data. Further research that explores such individual experiences in more detail will enable clarity in understanding the impact of SPS services on individuals' personal recovery.

Overall, the results support that recovery is a personal journey that takes time, where consumers may build a fulfilling and meaningful life to experience empowerment, expanded connections with others and community networks, an enriched sense of 'the self' and an enhanced quality of life founded on hope and selfdetermination $[10,11,15]$. The result that a few consumers' family members experienced similar opportunities for change and/or better life experiences suggest that future service providers and policy developers will gain from considering the potential benefits of SPS services to consumers, other individuals, and the community at large $[8,9,18,21,26]$.

These results are promising; however the use of data collected in the past and a self-selected and small sample reduced their transferability. Reliance on the data that were available restricted exploration to only the experiences that were captured in these data, and limited the full exploration of some of these experiences (e.g., lack of progression, motivational challenges and stressful experiences while undertaking services). Thus, it is essential to gain a more balanced and clearer understanding of the experiences outlined in this study. This may be done by using data across a broader scope, exploring consumers' experiences including their challenges in using the services and the types of support they gain from others in addition to key people (e.g., the Guides, support workers, family, friends and/or individuals or groups in the community) involved in SPS services. A further limitation related to the use of a small and selfselected sample that may have possessed unique characteristics, which might have influenced these outcomes. For example, most of the consumers that were already using services through the service provider may have already encountered positive experiences. These positive pre-SPS service experiences may have influenced the results of this study. Also, the review of information at a general group level that enabled for exploration of overall outcomes, limited insight into the individual differences of consumers' recovery experiences; thus, future 
research will benefit from exploring such experiences at a case-level. Further, although multiple data sources were explored using a rigorous systematic, consistent and allencompassing coding approach, and had undergone several quality checks to enhance objectivity, future research may benefit from using both qualitative and quantitative methods with real-time data collection to enable more clarity and certainty into the recovery experiences of consumers undertaking SPS services.

\section{Conclusions}

Most consumers at varied levels experienced four overarching categories of positive recovery experiences. This seemed directly related to them having access to individualised funds, high quality shared management and person-centred relationships, and the chance to selfdirect. In these SPS service experiences, consumers had improved emotional encounters and control over all aspects of their recovery that seemed to lead to behavioural, cognitive and/or emotional change and growth of quality of life. Thus, these results showed that newly provided SPS services in WA met most consumers' unique recovery needs that presented across all aspects of their lives, at varied levels in a meaningful, effective and timely manner.

\section{Competing interests}

The authors declare that they have no competing interests.

\section{Authors' contributions}

$A B$ conceived and designed the study, and $A B$ and SP coordinated and implemented the study. SP conducted the day-to-day management of data collection and collation, and coded the data for analysis. SP and AB analysed the data and developed the preliminary and final pilot model of service practice. All authors contributed to the preparation of the draft of this manuscript, and have approved the final manuscript for publication.

\section{Authors' information}

(1) Associate Professor Angus Buchanan Occupational Therapist and Deputy Head of the School of Occupational Therapy and Social Work, Curtin University (2) Sunila Peterson Provisionally Registered Psychologist and Research Associate in the School of Occupational Therapy and Social Work (3) Professor Torbjorn Falkmer Occupational Therapist and Senior Research Fellow in the School of Occupational Therapy and Social Work.

\section{Author details}

${ }^{1}$ School of Occupational Therapy \& Social Work, Curtin University, Perth, WA, Australia. ${ }^{2}$ Rehabilitation Medicine, Department of Medicine and Health Sciences (IMH), Faculty of Health Sciences, Linköping University \& Pain and Rehabilitation Centre, UHL, County Council, Linköping, Sweden. ${ }^{3}$ School of Occupational Therapy, La Trobe University, Melbourne, Vic., Australia.

Received: 12 December 2013 Accepted: 27 May 2014 Published: 5 June 2014

\section{References}

World Health Organization: World Conference on Social Determinant of 1.Health - Summary Paper. Switzerland: WHO Press; 2012.

2. Borg M, Karlsson B, Tondora J, Davidson L: Implementing person-centred care in psychiatric rehabilitation: what does this involve? Isr J Psychiatr Relat Sci 2009, 46:84-93.

3. Mental Health Commission of Western Australia: Informing the Development of a Quality Assurance Framework for Mental Health in Western Australia: Interim Report May / June 2011. [http://www.mentalhealth.
wa.gov.au/Libraries/pdf_docs/WA_QA_Interim_Report_FINAL_DRAFT_12_ June_2011_2.sflb.ashx]

4. Wade DT, Halligan PW: Do biomedical models of illness make for good healthcare systems? BMJ 2004, 329:1398-1401.

5. Deacon BJ: The biomedical model of mental disorder: a critical analysis of its validity, utility, and effects on psychotherapy research. Clin Psychol Rev 2013, 33:846-861.

6. Ogden J: An introduction to health psychology. [http://www.mcgraw-hill. co.uk/openup/chapters/0335214878.pdf]

7. Angermeyer MC, Matschinger H, Schomerus G: Attitudes towards psychiatric treatment and people with mental illness: changes over two decades. Br J Psychiatr 2013, 203:146-151.

8. Alakeson $\mathrm{V}$ : The contribution of self-direction to improving the quality of mental health services. [http://aspe.hhs.gov/daltcp/reports/2007/ MHslfdir.pdf]

9. Leadbeater C, Bartlett J, Gallagher N: Making it Personal. [http://www. partnerships.org.au/Making\%20lt\%20Personal.pdf]

10. Siu BWM, Ng BFL, Li VCK, Yeung YM, Lee MKL, Leung AYH: Mental health recovery for psychiatric inpatient services: perceived importance of the elements of recovery. East Asian Arch Psychiatr 2012, 22:39-48.

11. Andresen $R$, Oades $L$, Caputi $P$ : The experience of recovery from schizophrenia: towards and empirically validated stage model. Aust New Zeal J Psychiatr 2003, 37:586-594.

12. Anderson KK, Fuhrer R, Malla AK: There are too many steps before you get to where you need to be: Help seeking by patients with first episode psychosis. Journal of Mental Health 2013, 22:384-395.

13. Engel GL: The need for a new medical model: a challenge for biomedicine. Science 1977, 196:129-135.

14. Mental Health Commission of Western Australia: Mental Health 2020: Making it Personal and Everybody's Business - Reforming Western Australia's Mental Health System. [http://www.mentalhealth.wa.gov.au/ media_resources/policies.aspx]

15. Slade $\bar{M}$ : Measuring recovery in mental health services. Isr J Psychiatr Relat Sci 2010, 47:206-212.

16. Bradshaw W, Roseborough D, Peterson-Armour M: Recovery from severe mental illness: the lived experience of the initial phase of treatment. Int J Psychosoc Rehabil 2006, 10:123-131.

17. Peterson S, Buchanan A, Falkmer T: The impact of services that offer individualised funds, shared management, person-centred relationships, and self-direction on the lived experiences of consumers with mental illness. Int J Ment Health Syst 2014, 8:20.

18. Cook JA, Russell C, Grey DD, Jonikas JA: Economic grand rounds - a selfdirected care model for mental health recovery. Psychiatr Serv 2008, 59:600-602.

19. Hewitt-Taylor J: How personal health budgets may affect community nursing teams. Br J Community Nurs 2008, 13:362-366.

20. Disability Services Commission: Shared Management Policy. [http://www disability.wa.gov.au/reform1/reform/sector_development/ shared_management/]

21. Coyle D: Impact of person-centred thinking and personal budgets in mental health services: reporting a UK pilot. $J$ Psychiatr Ment Health Nurs 2011, 18:796-803.

22. Bernier A, Dozier M: The client-counselor match and the corrective emotional experience: evidence from interpersonal and attachment research. Psychother Theor Res Pract 2002, 39:32-43.

23. Miller RC: The somatically preoccupied patient in primary care: use of attachment theory to strengthen physician-patient relationships. Osteopathic Med Prim Care 2008, 2:6-16.

24. Teyber E: Interpersonal Process in Therapy: An Integrative Model. USA: Brooks/ Cole; 2006.

25. Mental Health Coordinating Council: Self-Directed Funding and the Community Managed Mental Health Sector: Opportunities and Challenges. 201, Sydney Australia: Mental Health Coordinating Council; [http://www. mhcc.org.au/media/11952/self-directed-funding-cmos-opportunitieschallenges-14-11-2011.pdf]

26. Glendinning C, Challis D, Fernandez J, Jacobs S, Jones K, Knapp M Manthorpe J, Moran N, Netten A, Stevens M, Wilberforce M: Evaluation of the Individual Budgets Pilot Programme - Final Report. London: University of York Kings College; 2008.

27. Shen C, Smyer MA, Mahoney K, Loughlin DM, Simon-Rusinowitz L, Mahoney EK: Does mental illness affect consumer direction of community-based 
care - lessons from the Arkansas cash and counseling program. Gerontologist 2008, 48:93-104.

28. National Steering Group: Self-directed services and personal budgets strategy paper 2012-2013. [http://www.partnerships.org.au/Strategy\% 20Paper\%20Self-Directed\%20Services\%20and\%20Personal\%20Budgets.pdf]

29. Jorm A: Mental health literacy: empowering the community to take action for better mental health. Am Psychol 2012, 67:231-243.

30. Kartalova-O'Doherty Y, Stevenson C, Higgins A: Reconnecting with life: a grounded theory study of mental health recovery in Ireland. J Ment Health 2012, 21:136-144

31. Roe D, Lysaker PH: Concerns and issues that have emerged with the evolution of evidence-based practice. J Ment Health 2012, 21:427-429.

32. Australian Bureau of Statistics: 4326.0 - National Survey of Mental Health and Wellbeing: Summary of Results. Canberra: Australian Bureau of Statistics; 2007 [http:/www.abs.gov.au/ausstats/abs@.nsf/Latestproducts/4326.0Main\% 20Features32007? opendocument\&tabname $=$ Summary $\&$ prodno $=4326.0$ \&issue $=2007 \&$ num $=\&$ view]

33. Charmaz K: Grounded theory. In Rethinking Methods in Psychology. Edited by Smith JA, Harre R, Van Langenhove L. London: SAGE Publications; 2001:27-49.

34. Langdridge D: Grounded theory. In Langdridge, Introduction to Research Methods and Data Analysis in Psychology. Edinburgh Gale: Pearson Education Limited; 2004:293-306.

doi:10.1186/1752-4458-8-23

Cite this article as: Buchanan et al.: A qualitative exploration of the recovery experiences of consumers who had undertaken shared management, person-centred and self-directed services. International Journal of Mental Health Systems 2014 8:23.

\section{Submit your next manuscript to BioMed Central and take full advantage of:}

- Convenient online submission

- Thorough peer review

- No space constraints or color figure charges

- Immediate publication on acceptance

- Inclusion in PubMed, CAS, Scopus and Google Scholar

- Research which is freely available for redistribution 